\title{
Rising markups and optimal redistributive taxation
}

\author{
Eren Gürer ${ }^{1}[$ ]
}

Accepted: 23 October 2021 / Published online: 19 December 2021

(C) The Author(s) 2021

\begin{abstract}
This study explores the implications of rising markups for optimal Mirrleesian income and profit taxation. Using a stylized model with two individuals, the main forces shaping welfare-optimal policies are analytically characterized. Although a higher profit tax has redistributive benefits, it adversely affects market competition, leading to a greater equilibrium cost-of-living. Rising markups directly contribute to a decline in optimal marginal taxes on labor income. The optimal policy response to higher markups includes increasingly relying on the profit tax to fund redistribution. Declining optimal marginal income taxes assists the redistributive function of the profit tax by contributing to the expansion of the profit tax base. This response alone considerably increases the equilibrium cost-of-living. Nevertheless, a majority of the individuals become better off with the optimal policy. If it is not possible to tax profits optimally, due, for example, to profit shifting, increasing redistribution via income taxes is not optimal; every individual is worse off relative to the scenario with optimal profit taxation.
\end{abstract}

Keywords Markups · Optimal redistribution · Imperfect competition · Taxation

JEL Classification D43 $\cdot \mathrm{H} 21 \cdot \mathrm{H} 25$

\footnotetext{
I am grateful to Alfons J. Weichenrieder for his guidance and continuous support. I would also like to thank Ariana Gilbert-Mongelli, Alexander Ludwig, Besart Avdiu, Danny Yagan, Emmanuel Saez, Florian Scheuer, Georg Dürnecker, Hakki Yazici, Jan Eeckhout, Jonas Loebbing, Onursal Bagirgan, Osman Kücüksen, Selen Yildirim, participants of the Spring 2020 Visitors Workshop at UC Berkeley IRLE, seminar participants at Goethe University Frankfurt, Marmara University, Ozyegin University, TED University, Catholic University of Milan, Stavanger Business School, Umeå University, Middle East Technical University, participants of 8th Mannheim Tax Conference for providing valuable comments and discussions.
}

\section{Eren Gürer}

guerer@wiwi.uni-frankfurt.de

1 Goethe University, Frankfurt, Germany 


\section{Introduction}

A lack of competitive pressure allows firms to set prices higher than marginal costs. Recent empirical studies report that markups, the wedge between marginal costs and prices, are on the rise in many countries across the globe (Loecker and Eeckhout 2018), including the USA (Loecker et al. 2020; Hall 2018). As a result, the welfare of the individuals, whose wages are a part of marginal costs, declines due to a higher cost-of-living. Because of declining marginal utility, such an effect is particularly detrimental to the indirect utility of poorer individuals. Furthermore, markups act as a distortion on labor supply and, thus, have a negative impact on efficiency. ${ }^{1}$ Overall, rising markups may create a case for the government to utilize its tax policies in order to re-optimize the trade-off between equity and efficiency.

The literature that considers redistributive taxation in conjunction with market power either conducts policy experiments with the profit tax (Boar and Midrigan 2019) or exclusively focuses on income taxes in settings where $100 \%$ profit tax is optimal (Kaplow 2019; Kushnir and Zubrickas 2019). It might, however, prove important to consider the interplay between the two policy tools. Ultimately, the two taxes jointly determine the state of competition and the total tax revenue in an economy. I explicitly model the strategic interactions between firms in a monopolistic competition setting in order to study the joint optimization of income and profit taxation. Atesagaoglu and Yazici (2020) explore the ramifications of higher markups for optimal capital and labor income taxation. Their study, however, abstracts from redistributive concerns. Scheuer (2014) studies simultaneous optimization of labor income and profit taxes in a setting with perfect competition. The purpose of this study, on the other hand, is to account for the redistributive taxation implications of market imperfections brought about by increasing markups.

How does a government with redistributive motives optimally adjust its corporate profit and labor income tax mix as markups rise? Should the corporate profit tax decrease to stimulate competition or should it increase to extract higher profit tax revenues that can be redistributed to the needy? What is the role of optimal Mirrleesian income taxes? This study investigates the optimal policy rules that address these questions.

I utilize a general equilibrium model featuring individuals that are heterogeneous in their earning abilities. Production is performed in two stages. A finite set of monopolistically competitive firms supply intermediate goods by using labor as the only input. This sector exhibits endogenous firm entry and, hence, generates endogenous markups which decrease in the number of firms. The final good producer aggregates the intermediate inputs in a perfectly competitive environment and sells the final goods to the individuals. A utilitarian government maximizes social welfare by simultaneously choosing its flat profit tax rate and Mirrleesian labor income tax scheme.

\footnotetext{
${ }^{1}$ Barkai (2020) and Loecker et al. (2020) argue that the profit share in the US economy has been increasing at the expense of the labor share since the $80 \mathrm{~s}$.
} 
Crucially, an increase in fixed production costs in the intermediate goods sector reduces the number of firms (i.e., by distorting $R \& D$ activities) and increases the wedge between prices and marginal costs. Whereas marginal costs of intermediate goods firms correspond to the wage rates of the individuals, prices of the intermediate goods factor into the cost-of-living. As a result, the real wages of the individuals decline. Furthermore, the reduction in real wages acts as a distortion of labor supply due to the substitution effect and, hence, leads to efficiency losses.

Novel formulas for optimal profit and labor income taxes are presented in a stylized two-type model. The optimal profit tax primarily depends on three factors: $(i)$ the Price Effect, (ii) the Tax Base Effect and (iii) the social value of taxable profits. Accordingly, (i) captures the distortive effects of the profit tax on competition, which leads to higher equilibrium cost-of-living. Thus, greater $(i)$ tends to reduce the optimal profit tax. Furthermore, (ii) and (iii) are related to the redistributive prospects and contribute to an increase in the profit tax. The sign and magnitude of the optimal profit tax are determined by the counteraction of these two motives. The expression for optimal marginal labor income taxes, on the other hand, incorporates an additional term to the standard Stiglitz (1982) formula. This new term tends to reduce labor distortions as markups increase in order to restrict the contraction in total output.

For the purposes of numerical simulations, I construct a benchmark US economy and estimate the fixed production costs that would yield a 20-percentage-point increase in the markups. Subsequently, I solve for and compare the optimal profit and labor income tax mix in the two states of the economy: with low and high fixed production costs. Optimal policy, in response to higher fixed costs, includes increasing the profit tax, despite its distortive effect on market competition. One important reason for this result is the simultaneous decline in optimal marginal income taxes. Reduced labor distortions incentivize higher labor supply, contributing to the expansion in the profit tax base, which is taxed at a higher rate with the optimal policy. A policy experiment suggests that, despite considerably depressing the real wages, the optimal policy makes almost all the individuals better off.

In a next step, I consider a scenario where the profit tax does not have distortive effects on the competition due to fixed costs being fully deductible from profits. As a result, a $100 \%$ profit tax is optimal. Exogenously restricting the profit tax to be less than $100 \%$, I investigate optimal labor income tax policies. I find that the optimal income taxes are almost stable as markups rise. This response does not exhibit increased redistribution. The social welfare, especially at the bottom of the distribution, is lower in comparison with the scenario with optimal profit taxation. An interpretation of this outcome is that the optimality of a redistributive response crucially relies on an operative profit tax.

In an extension, I perform a reduced-form corporate profit shifting exercise. The results suggest that the government's willingness to increase the profit tax, in response to higher markups, declines with the magnitude of the profit base elasticity. In other words, profit shifting may endogenously render the profit tax partially inoperative, preventing an otherwise optimal redistributive response. This analysis highlights the importance of fixing the profit shifting loopholes especially in the era of rising markups. 
The analyses thus far exploit higher fixed production costs as the underlying market mechanism that leads to greater markups by reducing the intensity of market competition. Indeed, there is mounting empirical evidence of increasing fixed costs (presented below). Nevertheless, keeping fixed costs constant, I consider increasing collusive behavior as an alternative reason for higher markups. Fundamental conclusions do not change. Hence, results should not be attributed to a specific feature of the fixed costs.

Related Literature. Recent empirical evidence reports a slowdown in business dynamism (Decker et al. 2016; Pugsley and Sahin 2018) and an increase in markups (Loecker et al. 2020; Hall 2018) in the USA. Rising fixed costs can explain these stylized facts by imposing barriers for market entry and, hence, hampering competitiveness (Colciago and Mechelli 2020; Ridder 2020). Various arguments for the underlying causes of rising fixed costs include technological change (Acemoglu et al. 2020; Ridder 2020; Grullon et al. 2019; Bessen 2017), demographic change (Karahan et al. 2019; Hopenhayn et al. 2018), a slow-down in research productivity (Bloom et al. 2020) and increasing regulations (Gutiérrez and Philippon 2019). ${ }^{2}$

Abstracting from redistributional issues, a recent strand of the literature studies different forms of taxation with market imperfections and strategic interactions which allow for endogenous entry and markups. See Coto-Martínez et al. (2007) (capital income and profit taxes), Colciago (2016) (labor and dividend income taxes), Etro (2018) (labor, dividend and capital income taxes), Bilbiie et al. (2019) (dividend income and consumption taxes) and Avdiu (2018) (capital and labor income taxes in developing countries). I contribute to this body of literature by studying optimal labor income and profit taxation with a government that has redistributive concerns.

This study is most closely related to the analysis of optimal redistributive taxation in imperfectly competitive markets. To the best of my knowledge, endogenous firm entry is assumed away in a majority of the studies. An exception is Boar and Midrigan (2019), which is discussed below. One strand of the literature studies optimal Mirrleesian income taxation with firms that have monopsony power (Hariton and Piaser 2007; da Costa and Maestri 2018; Hummel 2020). Kaplow (2019) examines optimal labor income taxation in a setting where firms charge a constant and exogenous markup over marginal costs. In his setting, tax policies do not affect markups and a $100 \%$ profit tax is optimal. Under various market structures, Kushnir and Zubrickas (2019) investigate optimal Mirrleesian taxation, accounting for endogenous price setting and progressively distributed firm profits. As emphasized above, Kushnir and Zubrickas (2019) do not model endogenous firm entry and do not solve for the optimal profit tax which are the key aspects of this study.

\footnotetext{
${ }^{2}$ An alternative reasoning for increasing markups is the reallocation of economic activity towards the most productive organizations, i.e., superstar firms (Autor et al. 2020). As noted in Colciago and Mechelli (2020), the two explanations can be true for different industries (or countries) at the same time. Departing from the empirical evidence on increasing fixed costs, this study focuses on the market power explanation of rising markups.
} 
Via policy experiments, Boar and Midrigan (2019) investigate aggregate and distributional consequences of product market interventions and the profit tax. Their model features monopolistic competition and heterogeneous producers. Income taxes are used to balance the government budget. Findings of Boar and Midrigan (2019) suggest that, for a given markup, increasing the profit tax heavily discourages market entry, thereby reducing total welfare. In this study, I assume away producer heterogeneities, but simultaneously optimize profit and labor income taxes in response to increasing markups.

Most relatedly, Eeckhout et al. (2021) studied optimal labor income and entrepreneurial profit taxation under increasing market power. Eeckhout et al. (2021) modeled two separate fixed occupations: entrepreneurs and workers. Entrepreneurs employ workers and earn entrepreneurial income which can be considered as profits. The government maximizes welfare by tailoring distinct income tax schemes for workers and entrepreneurs. The exogenously set number of entrepreneurs determines market power. Unlike Eeckhout et al. (2021), this study assumes a uni-dimensional skill distribution, but allows the number of monopolistic competitors to be determined at the equilibrium. Thus, a linear variable profit tax rate can be utilized to optimize the trade-off between real wages and redistribution. The model of Eeckhout et al. (2021) can explicitly capture equity concerns due to the asymmetric distribution of profits. This is not possible in my framework because there are no excess profits. This study shows that, even in the absence of asymmetric excess profit distribution, the optimal variable profit tax rate increases due to the enlarged profit tax base, when it is set simultaneously with the optimal income taxes.

This paper is also related to Scheuer (2014), who studies optimal profit and labor income taxation by explicitly modeling entrepreneurship via a two-dimensional skill distribution. Scheuer (2014) abstracts from imperfect competition, which is the focus of this study.

Finally, Atesagaoglu and Yazici (2020) investigate the implications of exogenously increasing markups (and declining labor share) for optimal linear capital and labor income taxation. In their setting, the government does not have redistributive concerns and aims at financing an exogenous stream of expenditure. They find that it is optimal to increase the capital tax when the reduction in labor share is accompanied by a higher profit share. I exclusively focus on the interplay between income and profit taxation. The government optimizes the trade-off between greater redistribution versus a higher cost-of-living.

\section{The model}

\subsection{Individuals}

A unit continuum of individuals, indexed by their earning ability $n$, is distributed over the support $[\underline{n}, \bar{n}]:=\eta$ with density $f(n)$. Individuals make an intensive margin labor supply decision, $l(n)$, to earn gross labor income, $y(n)=w n l(n)$, where $w$ is the wage rate per efficiency unit of labor. Disposable income of an individual with ability $n$ reads: 


$$
c(n)=y(n)-T(y(n))
$$

where $T(y(n))$ denotes nonlinear labor income tax or subsidy.

Individuals are assumed to have identical separable preferences. They derive utility from consuming the final consumption good $z(n)$, (convex) disutility from the supply of labor, $l(n)$. That is:

$$
U(n)=u(z(n))-v(l(n)), \quad \forall n
$$

with $u_{z}>0, v_{l}>0, v_{l l}>0$. The final consumption good $z$ is sold at a price $P_{c}$ which can also be considered as the cost-of-living. Thus, the budget constraint of an individual satisfies $z(n)=\frac{c(n)}{P_{c}}$. As a result, all else being equal, every individual in the economy becomes worse off if the cost-of-living increases. Furthermore, an increase in the cost-of-living, $P_{c}$, leads to reduction in real wages per efficiency unit, $\frac{w}{P_{c}}$. Consequently, individuals decrease their labor supply.

\subsection{Production}

Production is performed in two stages. In the second stage of the production process, the final goods producer aggregates a set $J$ of $N$ intermediate goods, $x$, following Dixit and Stiglitz (1977):

$$
C=\left(\sum_{j \in J} x_{j}^{\frac{\sigma-1}{\sigma}}\right)^{\frac{\sigma}{\sigma-1}} .
$$

$C$ and $\sigma>1$, respectively, represent the aggregate amount of the final consumption good and the elasticity of substitution between intermediate inputs. Note that the final goods sector is perfectly competitive. Markups in the economy are generated through the monopolistically competitive intermediate goods sector. The maximization problem of the final goods producer reads:

$$
\max _{\left\{x_{j}\right\}_{j \in J}} P_{c} C-\sum_{j \in J} p_{j} x_{j}
$$

where $p_{j}$ denotes the price of the intermediate good $j$. Solving the problem for $x_{j}$ and exploiting the fact that there are no profits in the final goods sector yield an expression for the price of the final good or the cost-of-living:

$$
P_{c}=\left(\sum_{j \in J} p_{j}^{1-\sigma}\right)^{\frac{1}{1-\sigma}} .
$$

In the first stage of the production, each of the $N$ monopolistically competitive firms produces a single intermediate good or variety $x_{j}$. Throughout the analyses, a symmetric equilibrium is assumed for this sector. Hence, $x_{j}=x$ and $p_{j}=p$. Under the assumption of symmetry, (5) simplifies to: 


$$
P_{c}=p N^{\frac{1}{1-\sigma}}
$$

Importantly, the cost-of-living, $P_{c}$, increases in the price of the intermediate goods, $p$. It is shown below that $p$ is determined via the markup in the intermediate goods sector. The second term on the right-hand-side reflects the "taste-for-variety" and its effect on $P_{c}$ is discussed below.

Each intermediate good $x$ is produced linearly using labor as the only factor of input:

$$
x=\int_{n \in \eta} n l(n) \frac{f(n)}{N} d n .
$$

Following (Brakman and Heijdra 2004, p. 15), individuals are assumed to be perfectly mobile across intermediate goods producers. As a result, each intermediate goods producer employs the same set of differently skilled individuals and there is a single wage rate, $w$.

The maximization problem of the monopolistically competitive firms reads:

$$
\max _{x}(1-\tau)(p-w) x-\phi .
$$

Intermediate goods firms must pay a fixed production cost, $\phi$, and a flat rate profit $\operatorname{tax}, \tau$, over their variable profits in each state of the economy. Importantly, fixed production costs, $\phi$, are not deductible from the profits. Under this assumption, the variable profit tax rate, $\tau$, can be used by the government to perfectly control the number of firms in the intermediate goods sector. ${ }^{3}$ However, if $\phi$ is fully deductible from the profits, then $\tau$ represents a pure profit tax and, in this case, it cannot be used to control the equilibrium number of firms. Section 4 explicitly considers this scenario.

Throughout the study, I normalize the wage rate per efficiency unit labor, $w$, of the individuals to unity. Nevertheless, real wage rates of the individuals are determined at the equilibrium due to the changes in the cost-of-living, $P_{c}$, which is dependent on the intensity of the competition (number of firms, $N$ ). ${ }^{4}$

Solving (8) yields the optimal relationship between the wages and prices:

$$
w \mu\left(\sigma, N^{\star}\right)=p, \quad \mu=\frac{\varepsilon_{x, p}}{\varepsilon_{x, p}-1}
$$

where $\mu$ represents the markup, $N^{\star}$ is the equilibrium number of firms, and $\varepsilon_{x, p}=-\frac{\partial x}{\partial p} \frac{p}{x}$ denotes the price elasticity of intermediate input demand. Essentially,

\footnotetext{
${ }^{3}$ This assumption is equivalent to the setting in Coto-Martínez et al. (2007) where variable and fixed costs are taxed at different rates. As long as imperfect deductability of fixed costs is maintained, the government can exercise perfect control over $N$ via the choice of $\tau$.

${ }^{4}$ An alternative, but equivalent, approach would be to normalize $P_{c}$ to unity, and let $w$ be determined through general equilibrium.
} 
prices of the intermediate goods are a markup over the marginal costs, $w$. Once $w$ is normalized to unity, one can write $p=\mu$.

The expression for the elasticity of intermediate input demand, $\varepsilon_{x, p}$, is dependent on the type of monopolistic competition. Under Cournot quantity competition, the markup reads:

$$
\mu\left(\sigma, N^{\star}\right)=\frac{\sigma N^{\star}}{(\sigma-1)\left(N^{\star}-1\right)} .
$$

The crucial aspect is that the markup, $\mu$, declines with the equilibrium number of firms, $N^{\star}, 5$ which is also the case with Bertrand price competition. Thus, the fundamental results of the study would not change if Bertrand competition is considered. See Online Appendix A for derivation of (10) and the markup under Bertrand competition.

The common approach in the literature is to assume $N \rightarrow \infty$, which generates $\mu=\frac{\sigma}{\sigma-1}$. In this study, however, strategic interactions between firms are explicitly modeled and, therefore, $N^{\star}$ is determined endogenously at the equilibrium. Via (6) and (9), the cost-of-living reads $P_{c}=\mu N^{\star} \frac{1}{1-\sigma}$. Thus,

$$
\frac{d P_{c}}{d N^{\star}}=\frac{\partial \mu}{\partial N^{\star}} N^{\star} \frac{1}{1-\sigma}+\frac{1}{1-\sigma} N^{\star} \frac{\sigma}{\sigma-1}<0 .
$$

A higher equilibrium number of firms reduces the cost-of-living through two channels. As in Coto-Martínez et al. (2007), new firm entry to the market can be interpreted as R\&D. As new firms enter the market, competition and productivity in the economy increase, and thus, the cost-of-living declines. This is reflected in the first term on the right-hand-side. The second term represents the effect of the "taste-for-variety." Consumers prefer to diversify their consumption, and, as the number of varieties increases, demand for each variety declines. Due to complementarity between varieties, the same level of utility can be achieved with a lower cost-of-living.

Entry into the intermediate goods sector is determined endogenously via a zeroprofit condition. Intuitively, as long as there are positive profits that can be captured, firms continue entering. Specifically, I solve the following equation for $N^{\star}$ in order to determine the equilibrium number of firms (or, the number of intermediate goods):

$$
\pi=(1-\tau)\left(\mu\left(\sigma, N^{\star}\right)-1\right) x-\phi=0
$$

where $p-w=\mu-1$.

To sum up, in the first stage of the production process, monopolistically competitive intermediate goods producers employ labor to produce their outputs. These outputs are sold to a final goods producer, which aggregates them into homogeneous final goods. Under the assumption of symmetry, the equilibrium amount of final

5 That is $\frac{\partial \mu\left(\sigma, N^{\star}\right)}{\partial N^{\star}}=\frac{\sigma}{\sigma-1}\left(-\frac{1}{\left(N^{\star}-1\right)^{2}}\right)<0$, provided that $\sigma>1$ and $N^{\star}>1$. 
goods boils down to $C^{\star}=\left(N^{\star}\right)^{\frac{\sigma}{\sigma-1}} x^{\star}$ (see equation (3)). Final goods are sold to the consumers.

Notice that, in this framework, the amount $\left(x^{\star}\right)$ and number of intermediate goods or equilibrium number of firms $\left(N^{\star}\right)$ as well as the amount of final goods $\left(C^{\star}\right)$ are determined endogenously. A change in marginal income tax rates, for example, affects the amount of intermediate goods, $x^{\star}$, via (7) due to labor supply distortions. The change in $x^{\star}$, in turn, factors into the zero-profit condition, (12), and influences the number of intermediate goods. Similarly, the profit tax, $\tau$, also affects both of the outcomes. A shift in $\tau$ induces a change in the number of intermediate goods and, thus, markups, $\mu$, directly via the zero-profit condition. In addition, markups act as a distortion on labor supply (see the discussion below, around equation (18)) and, thus, further affect the number of intermediate goods as well as the amount of intermediate goods. Finally, changes in fixed costs also directly impact the mentioned production outcomes due to their influence on markups. Given that the amount of final goods is merely an aggregation of the intermediate goods, the amount of final goods is endogenous to governmental policies and fixed costs.

\subsection{Government}

A utilitarian government maximizes the sum of utilities over a concave social welfare function, $H($.$) , by choosing its nonlinear income tax, \{T(.)\}_{n \in \eta}$, and flat profit tax, $\tau$, policies. Following the conventional approach in the literature, pairs $\{c(n), y(n)\}_{n \in \eta}$, instead of $\{T(.)\}_{n \in \eta}$, are used as the control variables to solve for income tax policies. Social welfare is given by:

$$
S W F=\int_{n \in \eta} H(U(n)) f(n) d n .
$$

Government budget constraint reads:

$$
\int_{n \in \eta} T(y(n)) f(n) d n+\tau\left(\mu\left(\sigma, N^{\star}\right)-1\right) F=R .
$$

The first term in (14) represents the revenue over income taxes. Let $F:=N^{\star} x$ correspond to the aggregate amount of production in the intermediate goods sector; the second term captures the profit tax revenue over the variable profits of the intermediate goods firms. $R$ denotes the exogenous government revenue requirement.

The information structure of the model is standard Mirrleesian. The government observes the gross incomes, $y(n)$, of individuals but not their abilities, $n$. Thus, incentive compatibility constraints must be employed in order to prevent mimicking behavior. If the negative marginal rate of substitution between $c(n)$ and $y(n)$ decreases in $n$ at the second-best allocations (Spence--Mirrlees single-crossing 
condition), then incentive compatibility constraints can be replaced by the following differential equation: ${ }^{6}$

$$
\frac{d U(n)}{d n}=v_{l} \frac{1}{n^{2}} y(n)
$$

This constraint represents the law-of-motion between the indirect utilities assigned to the individuals of different types.

\subsection{Equilibrium}

Definition 1 General equilibrium is defined as a set of individual quantities $(\{y(n)$, $\left.c(n)\}_{n \in \eta}\right)$, firm quantities $(C, x, \pi, N)$ and prices $\left(p, P_{c}\right)$ such that, for given fixed production cost, $\phi$, government tax policies and spending $\left(\{T(y(n))\}_{n \in \eta}, \tau, R\right)$ :

(i) individuals maximize utility (2),

(ii) firms maximize profits (4) and (8),

(iii) labor market clears,

$$
N^{\star} x=\int_{n \in \eta} n l(n) f(n) d n,
$$

(iv) consumption good market clears,

$$
\frac{1}{P_{c}} \int_{n \in \eta} z(n) f(n) d n=C-\frac{1}{P_{c}} N^{\star} \phi-\frac{R}{P_{c}},
$$

(v) government budget satisfies (14).

\section{Profit tax is operative}

In this section, I maintain the maximization problem of the intermediate goods producers introduced in (8). Fixed costs, $\phi>0$, are not deductible from profits. Thus, $\tau$ denotes a tax on variable profits and can be used by the government to control the equilibrium number of firms.

\subsection{Analytical insights in a two-type economy}

This section provides analytical insights into the welfare-optimal policy rules utilizing a stylized version of the model introduced in Section 2. In the spirit of Stiglitz

\footnotetext{
${ }^{6}$ See, e.g., Ebert (1992) for more on the topic. Together with incentive compatibility constraints, Spence-Mirrlees single-crossing property implies that second-best allocations of $c(n)$ and $y(n)$ monotonically increase in $n$. Results of the numerical solutions are checked to ensure that monotonicity holds.
} 
(1982), the continuum of individuals is replaced by two discrete individuals: a high ability, $n^{H}$, and a low ability, $n^{L}$. The individuals exist in the economy with fractions $f_{H}$ and $f_{L}$, respectively. Considering two discrete individuals simplifies calculations while sufficing to illustrate the forces that form optimal policy rules.

As is standard in the literature, the definition of marginal income taxes follows from maximizing $U\left(n^{i}\right), i \in\{H, L\}$ with respect to $l(n)$. This yields:

$$
T^{\prime}\left(y\left(n^{i}\right)\right)=1-\frac{v_{l}}{u_{z}} \frac{1}{n} P_{c}, \quad i \in\{H, L\} .
$$

Note that a higher cost-of-living can be brought about by higher markups. This acts as a further distortion of labor supply. For a given $T^{\prime}$, higher markups lead to an increase in $P_{c}$. This, in turn, reduces the labor supply and overall efficiency of the economy due to the substitution effect.

Proposition 1 Let $\varepsilon_{P_{c}, N}:=\frac{d P_{c}}{d N} \frac{N}{P_{c}}<0$ and $\varepsilon_{\mu, N}:=\frac{d \mu}{d N} \frac{N}{\mu}<0$ be the elasticity of the cost-of-living and the markup with respect to the equilibrium number of firms. Denote $\psi_{P_{c}}:=\frac{\partial \mathcal{L}^{1}}{\partial P_{c}} P_{c}<0$ and $\psi_{\mu}:=\frac{\partial \mathcal{L}^{1}}{\partial \mu} \mu>0$ as the semi-elasticites of the social planner's Lagrangian, $\mathcal{L}^{1}$, with respect to the cost-of-living and the markup. Then, the optimal profit tax rate is characterized by

$$
1-\tau=\frac{\overbrace{\varepsilon_{P_{c}, N} \psi_{P_{c}}}^{\text {Price Effect }}+\overbrace{\varepsilon_{\mu, N} \psi_{\mu}}^{\text {Tax Base Effect }}}{\alpha(\mu-1) F}
$$

where $\alpha$ corresponds to the Lagrange multiplier associated with the government budget constraint and $F$ represents the total amount of production in the intermediate goods sector.

The optimal marginal income tax rates faced by the high-and low-types are characterized by

$$
\begin{gathered}
T^{\prime}\left(y\left(n^{H}\right)\right)=-(\mu-1), \\
T^{\prime}\left(y\left(n^{L}\right)\right)=T_{s}^{\prime}-(\mu-1) .
\end{gathered}
$$

The standard Stiglitz term, $T_{s}^{\prime}$, is not spelled out here for brevity.

See Appendix for the proof.

Hereafter, the equilibrium number of firms $N^{\star}$ is denoted as $N$. The government exercises perfect control over $N$ by choosing the profit tax. In (19), $\varepsilon_{P_{c}, N}$ and $\varepsilon_{\mu, N}$ denote elasticities of $P_{c}$ and $\mu$ with respect to $N$. Equations (10) and (11) suggest that both elasticities are negative. $\psi_{P_{c}}$ and $\psi_{\mu}$ represent the welfare impact of a percent change in $P_{c}$ and $\mu$ via the Price Effect and the Tax Base Effect. Higher prices reduce the real wages of the individuals and, thus, have a negative welfare effect, that is, 
$\psi_{P_{c}}<0 .{ }^{7}$. Higher markups increase the tax base for the profit tax and imply a positive welfare effect through the government budget constraint, $\psi_{\mu}>0$. Formulas for $\psi_{P_{c}}$ and $\psi_{\mu}$ are provided in Appendix, Equ. (46).

The Price Effect, $\varepsilon_{P_{c}, N} \psi_{P_{c}}>0$, tends to decrease the optimal profit tax. A strong Price Effect implies that the government should lower the profit tax in order to stimulate competition, increase the equilibrium number of firms, and reduce the costof-living. The Tax Base Effect, $\varepsilon_{\mu, N} \psi_{\mu}<0$, contributes to an increase in the profit tax. A greater Tax Base Effect generates a higher optimal profit tax, such that the government reduces $N$ to increase markups and its profit tax base. Finally, $\alpha$ denotes the Lagrange multiplier of the government budget constraint and, thus, the common scaling term in the denominator represents the social value of taxable profits. A higher social value of taxable profits results in a higher optimal profit tax. Overall, the second term in the numerator and the term in the denominator are related to redistribution, whereas the first term in the numerator aims at correcting the inefficient pricing due to market power. The optimal profit tax is determined by the counteraction of the two motives. ${ }^{8}$

Equations (20) and (21) represent the optimal marginal income taxes. Suppose that there are no markups in the economy. Accordingly, $\mu=1$. In this scenario, $T\left(y\left(n^{H}\right)\right)=0$ is consistent with the well-established zero-marginal income tax rate at the top result. $T\left(y\left(n^{L}\right)\right)$ only incorporates the standard Stiglitz (1982) term, $T_{s}^{\prime}$, whose properties are well-known from the earlier literature. This term is not written out here for brevity, but the derivation is provided in Appendix. When $\mu>1$, the optimal policy rule is to reduce marginal income taxes by the absolute size of markups, compared to a no markup benchmark. As markups rise, there are two reasons for a government to reduce labor distortions and amplify the total production in the intermediate goods sector, $F$. First, the government could increase the amount of after-tax profits, $(1-\tau)(p-w) F$, to stimulate the competition and increase the equilibrium number of firms. Second, the government can increase its profit tax revenue, $\tau(p-w) F$. When the two motivations are brought together, however, $\tau$ is cancelled out. Higher markups directly contribute to a decline in optimal marginal income taxes.

\subsection{Numerical simulations}

This section simulates a rise in fixed production costs, which corresponds to a 20-percentage-point increase in the markups of a benchmark US economy and numerically solves for the optimal policy rules. Unlike the two-type setting of the previous section, economy is populated by a unit continuum of individuals.

\footnotetext{
7 Furthermore, it is shown in Appendix that higher $P_{c}$ renders mimicking more attractive, thereby stressing the incentive compatibility constraint.

8 Another way of reading the formula for the optimal profit tax is as follows. Note that the equilibrium number of firms is determined by the amount of after-tax profits; see (12). Hence, the social value of after-tax profits must be equal to the welfare impact of a percent increase in $N$. This can be seen by multiplying the left-hand side of (19) by the denominator on the right-hand side.
} 
Table 1 Summary of Parameterization

\begin{tabular}{lll}
\hline Parameter & Description & Values \\
\hline$\left(\mu_{s}, \sigma_{s}\right)$ & Log-normal part of the skill distribution (Kanbur and Tuomala 2013) & $\left(e^{-1}, 0.7\right)$ \\
$\alpha_{p}$ & Pareto parameter (Saez 2001) & 2 \\
$\epsilon$ & Elasticity of labor supply (Chetty 2012) & 0.33 \\
$\sigma$ & Elasticity of substitution (intermediate value of empirical estimates) & 4 \\
$\rho$ & Inequality aversion of the government (implies a logarithmic SWF) & 1 \\
$\phi_{1}, \phi_{2}$ & Fixed production costs (calibrated to match markups) & $0.01,0.158$ \\
Benchmark US Economy & \\
$t$ & Progressivity parameter (Heathcote et al. 2017) & 0.181 \\
$\lambda_{r}$ & Matches the profit- and income-tax-rev.-to-GDP ratio (OECD 2017, & 1.17 \\
$R$ & $\quad$ Table 4.69) & \\
\hline
\end{tabular}

Notes: All the parameters except for $\phi$ are set exogenously. In a benchmark US economy, $\phi_{1}=0.01$ and $\phi_{2}=0.158$, respectively, match the empirically observed average markups in the USA in 1987-88 and 2015-16 (Loecker et al. 2020)

Section 3.2.1 presents the functional forms used in the simulations. Section 3.2.2 provides the details regarding the calibration procedure. Section 3.2.3 numerically demonstrates the change in optimal policies in response to higher fixed costs (or markups). Finally, Section 3.2.4 performs a policy experiment to pin down the welfare benefits of optimally adjusting the tax mixture.

\subsubsection{Simulation specifications}

I assume quasi-linear preferences and exclude the income effects on labor supply:

$$
U(n)=\frac{c(n)}{P_{c}}-\frac{l(n)^{1+\frac{1}{\epsilon}}}{1+\frac{1}{\epsilon}} .
$$

This is in accordance with the earlier Mirrleesian optimal income tax literature (Diamond 1998; Rothschild and Scheuer 2013; Lockwood and Weinzierl 2015) and is supported by the empirical findings. Gruber and Saez (2002), for example, find small and insignificant income effects for the case of reported incomes.

With quasi-linear preferences, real consumption enters linearly to the preferences of the individuals. Thus, a concave social welfare function is required to introduce redistributive concerns to the government. I specify a generalized social welfare function:

$$
H(U(n))=\left\{\begin{array}{lll}
\log (U(n)), & \text { if } & \rho=1 \\
\frac{U(n)^{1-\rho}-1}{1-\rho}, & \text { if } & \rho \neq 1
\end{array}, \quad \rho>0\right.
$$

where $\rho$ determines the concavity and, thus, inequality aversion of the government. 
In order to calibrate fixed production costs, $\phi$, the tax system in the US economy must be approximated. According to Heathcote et al. (2017), the following tax-scale function well-approximates the US tax system:

$$
T(y(n))=y(n)-\lambda_{r} y(n)^{1-t},
$$

where $t$ captures the progressivity of the tax system and $\lambda_{r}$ can be used to match the net tax revenue.

\subsubsection{Calibration}

A summary of the parameters used in the simulations is provided in Table 1. Following the earlier literature, I assume a log-normal earnings ability distribution appended with a Pareto tail. Mean and the standard deviation of the log-normal section, $\left(\mu_{s}, \sigma_{s}\right)$, are set to $\left(e^{-1}, 0.7\right)$, which are found to offer a good approximation of the US hourly wage rate distribution. See, for example, Kanbur and Tuomala (2013) and Kushnir and Zubrickas (2019). For, approximately, the top 5\% of the population, I consider a Pareto tail with a Pareto parameter $\alpha_{p}=2$ (Saez 2001). Note that the density of the Pareto tail is scaled such that the resulting distribution is continuous at the cut-off. In the next step, appended distribution is properly scaled to ensure that it integrates to one.

The Frisch elasticity of labor supply is chosen as 0.33 , a commonly employed value in the literature (Chetty 2012). Epifani and Gancia (2017) argue that empirical estimates of the elasticity of substitution between varieties, $\sigma$, lie within a range of 3 and 5. I conduct a brief literature review (see Online Appendix B) and find support for this argument. Thus, I proceed with an intermediate value of $4 .^{9}$ Inequality aversion of the government, $\rho$, is set to unity to imply a logarithmic social welfare function. Online Appendix $\mathrm{C}$ repeats the simulations for two alternative values, 0.5 and 2. Although the levels of the resulting policies vary, the fundamental conclusions remain robust.

The next step is to approximate taxes in the USA and to estimate the increase in fixed production costs, $\phi$. The main purpose is to capture increasing markups. In order to approximate the tax system in the USA, I set $t=0.181$ in (24), estimated by Heathcote et al. (2017), and a profit tax of 21\%. Subsequently, for a given $\lambda_{r}$, $\phi$ is calibrated to match the average markup in $1987-88, \mu=1.35,{ }^{10}$ and 2015 $16, \mu=1.55$, reported by Loecker et al. (2020). The procedure yields $\phi_{1}=0.01$ and $\phi_{2}=0.158$. Finally, after the calibration procedure, $\lambda_{r}$ is adjusted to match income- and profit-tax-revenue-to-GDP ratio, 11.7\%, in the USA in 1990 (OECD 2017, Table 4.69). This implies an exogenous government revenue requirement of

\footnotetext{
${ }^{9}$ I experiment with different values of $\sigma$ in the numerical simulations. The levels of tax policies differ for a given markup. Nevertheless, the directions of the changes in policies in response to rising markups are robust with respect to the value of $\sigma$ (not reported).

${ }^{10}$ Note that, with $\sigma=4$, even $N \rightarrow \infty$ yields $\mu=\frac{\sigma}{\sigma-1}=1.34$. Thus, I choose 1987-88 as the starting point where, approximately, $\mu=1.35$ according to Loecker et al. (2020).
} 

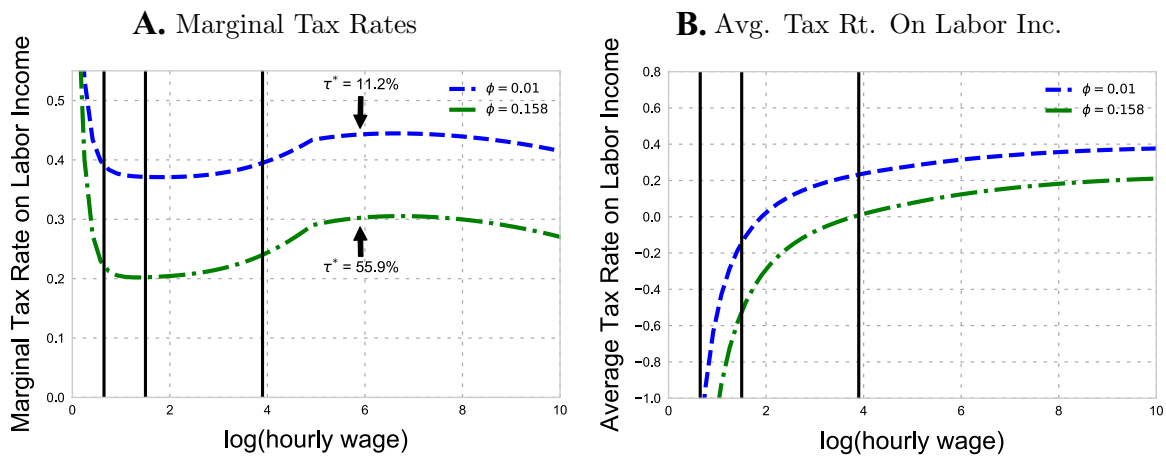

Fig. 1 Optimal tax mixture in response to rising markups. Note: Black solid lines represent the $10^{\text {th }}, 50^{\text {th }}$ and $90^{\text {th }}$ percentiles. Dashed blue lines represent the optimal marginal (left panel) and average (right panel) income tax policy of an economy with $\phi=0.01$. The associated optimal profit tax is $11.2 \%$. Dashed-dotted green lines represent the optimal income tax policies when $\phi=0.158$. The associated optimal profit tax is $55.9 \%$ (Colour figure online)

Table 2 Numerical values of the terms in the optimal profit tax

\begin{tabular}{llll}
\hline & SVTP & Numerator & $\tau^{\star}$ \\
\hline$\phi=0.01$ & 0.579 & 0.514 & 0.112 \\
$\phi=0.141$ & 0.828 & 0.365 & 0.559 \\
\hline
\end{tabular}

SVTP: Social value of taxable profits, Numerator: The sum of the Price Effect and the Tax Base Effect. The optimal profit tax reads $\tau^{\star}=1-\frac{\text { Numerator }}{\text { SVTP }}$

$R=0.41$ in the benchmark US economy. This revenue requirement is fed into the model when solving for optimal policies.

\subsubsection{Optimal policy rules in response to rising markups}

Figure 1 demonstrates the optimal policy mixture for the two states with different fixed costs, 0.01 and 0.158 . Recall that increasing $\phi$ from 0.01 to 0.158 implies a 20 percentage point increase in the average markup of a benchmark US economy.

The left panel of Fig. 1 suggests that, as fixed costs rise, the optimal response is to increase the profit tax from $11.2 \%$ to $55.9 \%$, combined with a substantial reduction in marginal income taxes. Recall that the government optimizes its policy tools simultaneously and adjustments in one policy tool affect the other one. Thus, the interpretation of the decisions must be interlinked. Essentially, the redistributive motives on the profit tax dominate, leading to its increase. As mentioned earlier, higher markups, which are further driven up by the increase in the profit tax, distort labor supply. Nevertheless, the government reduces the optimal marginal income taxes in order to subsidize labor and, thus, limit the decline in total output. This assists the redistributive function of the profit tax by contributing to the expansion in the profit tax base. 
In order to reinforce this intuition, I investigate the changes in the numerical values of the terms in the optimal profit tax given in (19). Note that the social value of taxable profits, $\alpha(\mu-1) F$, is not dependent on whether the analysis is conducted over two types of individuals or a continuum of individuals. Thus, it can be directly calculated. Because the optimal profit tax is known, the total value of the terms in the numerator can be recovered. The terms in the numerator are the Price Effect and the Tax Base Effect.

In Table 2, the column denoted by "SVTP" (social value of taxable profits) represents the value of the denominator in (19), whereas the column named as "Numerator" displays the total value of the terms in the numerator. Table 2 suggests that both numerator and denominator of (19) change in favor of a higher optimal profit tax rate. The intuition laid out above is conveniently visible through the changes in the social value of taxable profits. First, higher absolute markups, $(\mu-1)$, directly contribute to an increase in the social value of taxable profits by expanding the profit tax base. Second, as explained above, the marginal income taxes decline upon an increase in markups (or fixed production costs) due to the additional terms in (20) and (21), restricting the decline in total output, $F$. As a result, reduction in marginal income taxes contributes to the expansion in the profit tax base, assisting the redistributive function of a higher profit tax.

The dominance of the Tax Base Effect against the Price Effect is a secondary channel and arises due to the interaction of the assumption of "taste-for-variety" and a decline in the number of firms, $N .{ }^{11}$ Nevertheless, the extension in Section 5.2 presents a scenario, in which the number of firms stays (approximately) constant and, thus, this secondary channel is excluded. In this case, the optimal profit tax still considerably increases due to greater social value of taxable profits. Overall, as markups rise, it can be argued that the increase in the Tax Base Effect absorbs, if not dominates, the increase in the Price Effect because both are driven by the changes in markups.

The right panel in Fig. 1 plots the average tax rates on labor incomes of the individuals. The economy with higher fixed costs, and markups, is associated with higher redistribution. Despite greater redistribution, labor income taxes on the richer individuals decline. Essentially, as markups rise, the optimal behavior of a government is to implement greater redistribution. This redistribution is funded by increasingly relying on the profit tax.

The finding that the optimal profit tax increases as markups rise resonates with Auriol and Warlters (2005), who offer an explanation for large informal sectors within developing countries. The authors argue that the governments of developing countries may intentionally increase the entry barriers to formal sectors. Such entry barriers result in higher market power and, thus, greater amount of profits which can be confiscated by the governments via a profit tax at low administrative costs.

\footnotetext{
11 This reflects the fact that elasticity of markup to number of firms, $\varepsilon_{\mu, N}$ is close to zero when there are many firms in the economy. As the number of firms decreases, $\varepsilon_{\mu, N}$ increases. $\varepsilon_{P_{c}, N}$, on the other hand, is already high before the change in the fixed costs, because of the second term on the right-hand-side of (6). As $N$ declines, $\varepsilon_{\mu, N}$ gradually catches up with $\varepsilon_{P_{c}, N}$.
} 




Fig. 2 Welfare implications of optimally adjusting the tax mixture. Note: Black solid lines represent the $10^{\text {th }}, 50^{\text {th }}$ and $90^{\text {th }}$ percentiles. The graph illustrates the changes in the indirect utilities of the individuals as a result of the government optimally responding to an increase in $\phi$, compared to the scenario in which the government does not change its policies (Colour figure online)

\subsubsection{Policy experiment}

This section constructs a counterfactual economy to provide insights into the welfare implications of the government's optimal policy response. In the counterfactual economy, fixed production costs are set at $\phi=0.158$. The government, on the other hand, applies the optimal policy rules of the scenario with $\phi=0.01$, shown as the marginal income taxes plotted by the blue dashed line in Fig. 1 and the profit tax rate of $11.2 \%$. Thus, the counterfactual economy can be viewed as a scenario in which the government is unresponsive to the increase in fixed production costs. The equilibrium quantities for $\phi=0.158$ are recalculated with the optimal policies of the scenario in which $\phi=0.01$.

Figure 2 demonstrates the real consumption-equivalent gains across the distribution as a result of the government optimally responding to the change in fixed production costs. This measure is recovered by calculating the percentage of real consumption that must be added on top of the indirect utilities with the suboptimal policies such that resulting indirect utilities equal those with optimal policies. Note that labor supplies are kept constant. The markup of the counterfactual economy reads $\mu_{c f t}=1.526$, whereas the markup in the economy with optimal policies is $\mu_{\phi=0.158}=1.668$. Thus, the policy response of the government alone adds more than 14 percentage points to the markup. On the other hand, Fig. 2 suggests that the majority of the individuals are better off with the optimal policies, despite the sizable increase in the cost-of-living brought about by higher markups. This improvement in indirect utilities occurs either due to increased subsidies (for low incomes) or reduced labor income taxes (for middle, middle-high incomes). The average real consumption-equivalent gain generated by the optimal response is $4 \%$.

Figure 2 also suggests that a small fraction of high income individuals are worse off upon implementation of the optimal policy. These individuals exhibit very high 
earning abilities and are therefore severely affected by labor income distortions. The slight reduction in their indirect utilities implies that the additional distortions triggered by higher markups outweigh the benefits of the reduction in marginal income taxes. The analyses in this study miss the welfare implications of excess profit/dividend distribution. A detailed discussion of this limitation is provided in Section 6.2.

\section{Profit tax is not operative}

This section considers the possibility that the flat profit tax, $\tau$, cannot be used by the government as a policy tool in response to rising markups. Consider the generalized version of the maximization problem introduced in (8):

$$
\max _{x}(1-\tau)(p-w-(1-\beta) \phi) x-\beta \phi, \quad \beta \in[0,1] .
$$

The scenario considered in this section assumes $\beta=0$, which implies that fixed costs are fully deductible from the profits. Therefore, $\tau$ corresponds to a pure profit tax and cannot be used by the government to exercise control over the equilibrium number of firms, $N$. This possibility is also pursued in the representative individual framework of Coto-Martínez et al. (2007). The setting in this study, however, features heterogeneous individuals and a government with redistributive concerns. Thus, the optimal profit tax with fully deductible fixed costs is $100 \%$.

Considering, for example, the political constraints or profit shifting opportunities, ${ }^{12} \mathrm{I}$ assume there is an exogenous profit tax, $\tau<100 \%$. Thus, an alternative interpretation of this scenario could be that the government does not volunteer to use its profit tax instrument. ${ }^{13}$

\subsection{Analytical insights in a two-type economy}

This section provides analytical insights for the optimal marginal income taxes when the profit tax is set exogenously. As in Section 3.1, I assume that there is a high- and a low-type individual in the economy. The definition of marginal income taxes are the same as in (18).

Marginal income taxes, as usual, assume the role for optimizing the trade-off between equity and efficiency. On the other hand, when profit tax is not operative, they can additionally be used to exercise some control over the equilibrium number of firms. Combining (25) and (10) suffices to write $N\left(y\left(n^{H}\right), y\left(n^{L}\right)\right)$ with $\frac{\partial N}{\partial y\left(n^{i}\right)}>0$. Higher gross incomes (or labor supplies) expand after-tax profits, stimulating the competition and increasing the equilibrium number of firms.

\footnotetext{
12 Implications of profit shifting on the results of the case with an operative profit tax are explicitly studied in Section 5.1.

13 In the setting with an exogenous profit tax, specifying fixed costs as deductible or non-deductible from the profits has little effect on the results (not reported).
} 
A. Marginal Tax Rates



B. Avg. Tax Rt. On Labor Inc.

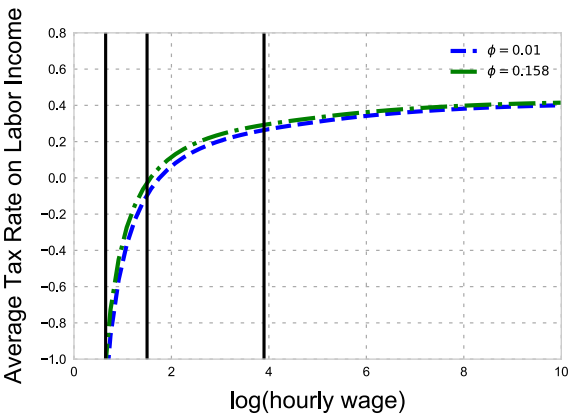

Fig. 3 Optimal income tax policies in response to rising markups. Note: Black solid lines represent the $10^{\text {th }}, 50^{\text {th }}$ and $90^{\text {th }}$ percentiles. Dashed blue lines represent the optimal marginal (left panel) and average (right panel) income tax policy of an economy with $\phi=0.01$. Dashed-dotted green lines represent the optimal income tax policies when $\phi=0.158$. Profit tax is exogenously set to $21 \%$ (Colour figure online)

Proposition 2 The optimal marginal income tax rates faced by the high-and lowtypes are characterized by

$$
\begin{gathered}
T^{\prime}\left(y\left(n^{H}\right)\right)=-\tau(\mu-1)-\frac{\partial N}{\partial y\left(n^{H}\right)} \frac{\Lambda_{N}}{\alpha f_{H}}, \\
T^{\prime}\left(y\left(n^{L}\right)\right)=T_{s}^{\prime}-\tau(\mu-1)-\frac{\partial N}{\partial y\left(n^{L}\right)} \frac{\Lambda_{N}}{\alpha f_{L}}
\end{gathered}
$$

with

$$
\Lambda_{N}:=\frac{d \mathcal{L}^{2}}{d N}=\overbrace{\frac{\partial P_{c}}{\partial N} \frac{\partial \mathcal{L}^{2}}{\partial P_{c}}}^{\text {Price Effect }}+\overbrace{\frac{\partial \mu}{\partial N} \frac{\partial \mathcal{L}^{2}}{\partial \mu}-\alpha \tau \phi}^{\text {Tax Base Effect }} \lessgtr 0
$$

where $\mathcal{L}^{2}$ denotes the social planner's Lagrangian and $\alpha$ corresponds to the Lagrange multiplier associated with the government budget constraint. The standard Stiglitz term, $T_{s}^{\prime}$, is not spelled out here for brevity.

See Appendix for the proof.

Compared to a perfect competition benchmark $\left(T^{\prime}\left(y\left(n^{H}\right)\right)=0, T^{\prime}\left(y\left(n^{L}\right)\right)=T_{s}^{\prime}\right)$, two additional terms appear in the optimal marginal income taxes: $\tau(\mu-1)$ and $\frac{\partial N}{\partial y\left(n^{i}\right)} \frac{\Lambda_{N}}{\alpha f_{i}}$. The former is related to the government's incentive to amplify total output and profits in the economy by subsidizing labor supply. That would help the government to raise higher profit tax revenue via the exogenous profit tax rate, $\tau$. Hence, this term contributes to a decline in optimal marginal income taxes.

Recall that the Price Effect and the Tax Base Effect were previously attributed to the profit tax. The latter terms in optimal marginal income taxes suggest that the 




Fig. 4 Welfare implications of the scenario with an inoperative profit tax in comparison with the scenario with an operative profit tax $(\phi=0.158)$. Note: Black solid lines represent the $10^{\text {th }}, 50^{\text {th }}$ and $90^{\text {th }}$ percentiles. The graph illustrates the increase or decrease in the indirect utility of the individuals, when the profit tax is not available relative to the scenario with an operative profit tax (Colour figure online)

Price Effect and the Tax Base Effect are internalized by marginal income taxes through $\Lambda_{N}$, which denotes the welfare effect of a unit change in $N$. Nevertheless, the impact of $\Lambda_{N}$ on optimal marginal income taxes is restricted to the extent that gross incomes (or labor supplies) of the individuals can affect the equilibrium number of firms. Therefore, $\Lambda_{N}$ is scaled by $\frac{\partial N}{\partial y\left(n^{i}\right)}$. A further discussion of $\Lambda_{N}$ is provided in Appendix.

\subsection{Numerical simulations}

Figure 3 presents the results of the numerical simulations in a similar fashion to those provided in Fig. 1. Parameterization is the same as in Table 1. The only addition is the exogenous profit tax rate of $21 \%$.

Drawing on (27), the following dynamics can be expected in response to higher fixed costs and markups. First, it is clear that $-\tau(\mu-1)$ becomes more negative and tends to reduce the marginal taxes. Second, the Price Effect contributes to a decline in $T^{\prime}$ for two reasons: $\left(i\right.$.) the welfare effect of a unit change in $P_{c}, \frac{\partial \mathcal{L}^{2}}{\partial P_{c}}$, increases due to the concavity of the social welfare function, and (ii.) $P_{c}$ is convex in $N$. Third, the Tax Base Effect becomes more negative, because $\phi$ increases and, similar to $P_{c}, \mu$ is convex in $N$. Thus, the Tax Base Effect counteracts the first two effects by applying upwards pressure on optimal $T^{\prime}$. Fourth, higher $P_{c}$ reduces the relative price of leisure, rendering mimicking more attractive. As a result, the classical Stiglitz term, $T_{s}^{\prime}$, increases to prevent mimicking.

Overall, as fixed costs rise, the first two effects tend to decrease the marginal income taxes, whereas the latter two effects contribute to an increase. Figure 3 suggests that all four effects almost perfectly cancel each other out. To sum up, when the government does not have access to the profit tax, redistributive concerns prevent a decline in 
A. When $\phi=0.158$

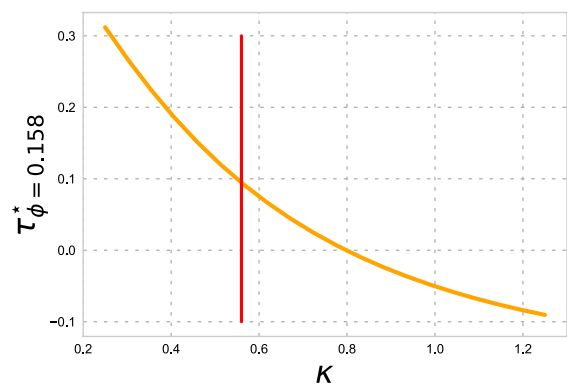

B. As $\phi$ increases from 0.01 to 0.158

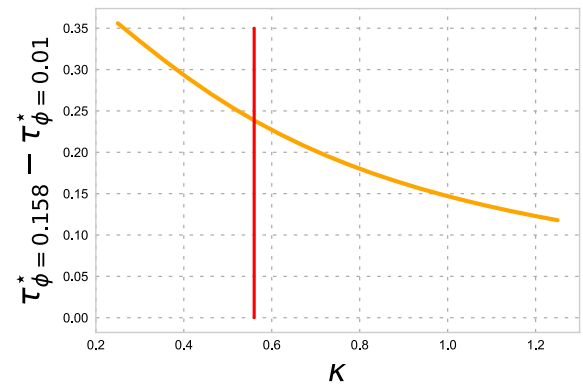

Fig. 5 Optimal profit tax with profit shifting . Note: The left panel presents the optimal profit tax with $\phi=0.158$. The right panel plots the optimal increase in the profit tax when fixed costs, $\phi$, increase from 0.01 to 0.158 . Red solid line in each panel indicates $\kappa=0.56$, the point where $18 \%$ of corporate profits are shifted abroad with a statutory corporate income tax of $35 \%$. This represents the situation in the US in 2013 according to Zucman (2014)

optimal marginal income taxes. On the other hand, the optimal governmental response is not associated with an increase in redistribution.

Figure 4 illustrates the welfare implications of the scenario with an inoperative profit tax in comparison with the scenario with an operative profit tax, when $\phi=0.158$. Figure 4 suggests that if optimal profit taxation is not possible, the picture presented in Fig. 2 is reversed. Increased cost of living reduces the indirect utilities of all the individuals. The decline in individual well-being is the starkest at the bottom of the distribution due to the absence of a redistributive response.

\section{Extensions}

\subsection{Profit shifting}

A central finding of this study, presented in Section 3.2.3, is that the optimal profit tax increases as the wedge between prices and marginal costs widens. It is well known from earlier work, however, that higher profit taxes incentivize corporations to employ profit shifting strategies. See Dharmapala (2014) for a survey of the empirical literature. As a result, higher profit taxes may not generate the desired level of redistribution in an open economy with mobile profits. Thus, in this section, I perform a reducedform analysis from the perspective of the government to investigate the effect of profit shifting on the main results with an operative profit tax.

Suppose a $1-g(\tau)$ fraction of the profits is shifted abroad where:

$$
g(\tau)=e^{-\kappa \tau} .
$$

The analyses in Section 3 correspond to a case with $\kappa=0$. Notice that the elasticity of the profit base, solely due to shifting behavior, with respect to the profit tax reads $\varepsilon_{g, \tau}=-\frac{\partial g(\tau)}{\partial \tau} \frac{\tau}{g}:=\kappa \tau$. Both $\kappa$ and $\tau$ increase the elasticity. Once a $1-g(\tau)$ fraction 
of the profits is shifted abroad, the government budget constraint provided in (14) is modified as:

$$
\int_{n \in \eta} T(y(n)) f(n) d n+\tau g(\tau)\left(\mu\left(\sigma, N^{\star}\right)-1\right) F=R .
$$

Tørsløv et al. (2018) argues that profit shifting might have adverse effects on competitiveness by reducing the effective tax rates on multinationals. In order to reflect this possibility, I assume that shifted profits are invested elsewhere and do not enter into the zero-profit condition, hampering competitiveness. ${ }^{14}$ This serves as a further barrier to entry and reduces the equilibrium number of firms. More specifically, I specify the zero-profit condition as:

$$
\pi=g(\tau)(1-\tau)(\mu(\sigma, \hat{N})-1) x-\phi=0 .
$$

As a result, remaining firms, such as multinationals, end up with higher markups. In Fig. 5, the red vertical line represents $\kappa=0.56$, with which a 35\% corporate statutory tax rate leads to $18 \%$ of the profits being shifted. This is reported by Zucman (2014) for the US corporate profits at 2013. The left panel of Fig. 5 presents the optimal profit tax for different $\kappa$ values. As $\kappa$ and, hence, the elasticity of the profit base increases, the optimal profit tax declines. This reflects the classical argument regarding tax competition. For very high elasticities, even subsidizing firms may become optimal.

The right panel of Fig. 5 plots the difference between the optimal profit tax with $\phi=0.158, \tau_{\phi=0.158}^{\star}$, and with $\phi=0.01, \tau_{\phi=0.01}^{\star}$. For higher $\kappa$ values, the optimal increase in the profit tax is less pronounced. To understand this, notice that the elasticity of the profit base with respect to $\tau, \varepsilon_{g, \tau}$, increases in $\kappa$. Hence, when $\kappa>0$, increases in $\tau$ further strengthen Price Effect by hampering competition and reduce the profit tax base, both through $g(\tau)$. These effects get stronger as $\kappa$ increases. Thus, a utilitarian government becomes less willing to raise the profit tax.

Admittedly, the analyses completed in this section are in reduced form. It is, however, possible to argue that profit shifting is a barrier that may prevent or undercut the effectiveness of a redistributive policy response-which is optimal as markups rise-because it limits the possibility of an adjustment in the profit tax. Thus, this section can also be viewed as an applied example of Section 4, where the profit tax is partly not operative.

\subsection{Collusive behavior}

In the analysis so far, higher markups are triggered by an increase in the fixed production costs. This section extends the model to incorporate collusive behavior of

\footnotetext{
14 If I assumed that hidden profits enter into the zero-profit condition, the adverse effect of an increase in the profit tax would be reduced. Thus, the government would be even more motivated to increase the profit tax.
} 
intermediate goods firms. ${ }^{15}$ The main objective is to reinforce the main findings by illustrating that they are not directly driven by higher fixed costs but rather are related to the increasing wedge between marginal costs and prices. Similar to the effect of higher fixed costs, firms exhibiting increasingly collusive behaviors would lead to higher equilibrium markups. However, contrary to fixed costs, collusive behavior is related to the beliefs of intermediate firms regarding industry's reaction to its output expansion. Thus, changes in collusive behavior do not impact the markups by lowering the equilibrium number of firms, as is the case with fixed production costs.

I employ the conjectural variation model by Bowley (1924), which has been recently used by Kushnir and Zubrickas (2019). Consider the maximization problem given in (8). The assumption implicit to the problem of monopolistically competitive firms is that price of the intermediate output is a function of the total amount of intermediate outputs, that is, $p\left(\sum_{j \in J} x_{j}\right)$. Beliefs of the intermediate goods firms can be represented as follows:

$$
\frac{d \sum_{i \neq j} x_{j}}{d x_{i}}=\theta .
$$

Under this assumption, the markup reads: ${ }^{16}$

$$
\mu=\frac{\sigma N}{\sigma N-(1+\theta)(N+\sigma-1)} .
$$

Throughout this study, I assumed that $\theta=0$. This means the industry is assumed to be unresponsive to the unit change in the maximizing firm's output. Notice that, with $\theta=0$, (33) simplifies to (10). When $\theta=-1$, total output of the industry is precisely reduced by the amount of the maximizing firm's marginal production. In this case, $\mu$ equals unity and, thus, the model becomes perfectly competitive. Finally, when $\theta=N-1$, firms maximize joint profits. This corresponds to perfect collusive behavior.

I set $\phi=0.08$, an intermediate value between 0.01 and 0.158 , and repeat the calibration exercise performed in Section 3.2.2 to determine appropriate $\theta$ values. For markups to rise from 1.35 to 1.55 in a benchmark US economy, $\theta$ must increase from -0.223 to 0.170 . Estimated values of $\theta$ suggest that markets must be more competitive than a standard monopolistic competition framework in order to generate a markup of 1.35 for the parameter values given in Table 1. Generating a markup of 1.55 , on the other hand, requires the accompanying market structure to be less competitive than monopolistic competition.

\footnotetext{
15 Increasing multimarket contact, for example, is known to enable collusive outcomes. See, e.g, Schmitt (2018) and Ciliberto and Williams (2014).

16 With (32), the second equality in (9) reads $\mu=\frac{\varepsilon_{x, p}}{\varepsilon_{x, p}-(1+\theta)}$. The derivation of (33) follows Online Appendix A.
} 
For estimated $\theta$ values, I reproduce the equivalents of Figs. 1 and 3. See Figs. D.1 and D.2, respectively, presented in Online Appendix D. While there are changes in quantitative results, fundamental policy implications are virtually the same. This suggests that results presented in the previous sections are largely driven by the increasing wedge between prices and marginal costs.

Table D.1 in Online Appendix D decomposes the values of the terms in the optimal profit tax formula, (19). Because the number of firms hardly changes upon an increase in collusive behavior, the total value of the terms in numerator is almost stable. As markups rise, changes in the Tax Base Effect absorb the changes in the Price Effect and an increase in the optimal profit tax is mainly driven due to the greater social value of taxable profits.

\section{Discussion}

\subsection{Production process}

The two-stage production process with intermediate goods is not a necessity. The purpose of this structure is to simplify analytical derivations related to the individual optimization problem. This setting is equivalent to renaming the outputs of monopolistically competitive firms as final goods and introducing the Dixit-Stiglitz aggregator into the individual sub-utility of consumption. However, utilizing a perfectly competitive final goods producer allows us to construct a simple and standard individual optimization problem.

In the main analyses, higher markups are triggered via an increase in fixed costs. An alternative approach would be to utilize the exogenous changes in the number of intermediate goods, $N$. Notice, however, that markups are determined via $\sigma$ and $N$ (see equation (10)). Elasticity of substitution parameter, $\sigma$, is set exogenously. Fixing also $N$ would imply exogenous markups, and, thus, the profit tax would not distort any margin. As a result, a $100 \%$ profit tax would be optimal. Nevertheless, it is possible to analyze optimal income taxes for a given profit tax in such a setting. Online Appendix E performs this analysis. Utilizing exogenous changes in $N$ and $\tau$, one can draw conclusions that are similar to those in the main text.

\subsection{Asset formation and excess profits}

A limitation of the current study is the absence of progressively distributed profit incomes. If increasing markups overlap with an increase in monopolistic excess profits (see, i.e., Loecker et al. (2020) and Barkai (2020)), and affluent individuals acquire a greater share of such profits ${ }^{17}$, disposable income inequality might be amplified. Hence, there might be ramifications for redistributive taxation.

\footnotetext{
17 The top 10\% claimed almost 100\% of dividends in the USA in 2012 (Saez and Zucman 2016, Table B23).
} 
A way of generating excess profits would be by eliminating endogenous entry via fixing the equilibrium number of firms, $N$. However, as mentioned in the previous section, the optimal profit tax in such a scenario is $100 \%$ (see also Online Appendix E).

Ideally, the aforementioned stylized fact should be captured via a model that comprises three elements: endogenous asset formation, excess profits, and capitallabor complementarities in production. In such a framework, excess profits would be distributed back to the individuals depending on asset ownership. Higher profit tax rates would distort asset demand and, thus, business dynamism.

It is possible to extend the model in this paper into a dynamic framework with endogenous asset formation and capital-labor complementarities. Nevertheless, it would not be possible to generate excess profits as long as endogenous entry via the zero-profit condition is maintained. Therefore, as in the current study, distortion of a higher profit tax rate on business dynamism would be captured implicitly via reductions in the amount of profits and, thus, the equilibrium number of firms (see the penultimate paragraph of Section 2.2.). As a result, the main results found in this study would possibly hold.

Another method of generating excess profits is by assuming that an exogenous fraction of firms exits the economy upon completion of entry. This assumption, however, can be criticized on the grounds of firms not behaving rationally when making their entry decisions. Nevertheless, the working paper version of this study, (Gürer 2021), employs an exogenous exit rate in a static framework and distributes excess profits exogenously. The effect on the main policy implications is limited. As a thought experiment, assume away all the distortive effects and redistributive benefits of the profit tax. The government does not have a tool to alter the distribution of excess profits. When excess profits are allowed, a variable profit tax rate can only affect their amount. Thus, the only policy-relevant aspect is the positive contribution of excess profits to indirect utilities. This affects the optimal policies of a utilitarian government minimally because the majority of the profits accrue to a small fraction of individuals who are already affluent. Other aspects related to the creation of variable and excess profits, such as increased cost-of-living and efficiency losses, are captured in the model utilized in this study. On the other hand, excess profits may have noteworthy welfare implications. In particular, the optimal response, which includes a higher profit tax rate, would render high-income individuals considerably worse off because excess profits represent the main income source in their budget.

Another possible approach might be to differentiate firms according to their fixed production costs. Suppose there are two distinct firms or sectors with high and low fixed costs. Furthermore, assume that the government cannot condition its tax policies to the sector. If the assumption of endogenous entry is preserved, the two sectors would produce different markups but still no excess profits. Hence, the same policy implications would presumably hold in response to a proportional increase in fixed costs. Alternatively, one may assume that there is endogenous entry only for the sector with high fixed costs and products of the two sectors are perfect complements (i.e., both sectors must produce the same number of intermediate goods). These assumptions are difficult to rationalize. Nevertheless, that would be a way of generating excess profits via the sector with low fixed costs. The role of the profit 
tax, however, would still be optimizing the trade-off between redistribution and competition. Thus, optimal policies would be affected minimally due to the argument presented in the previous paragraph.

Finally, Eeckhout et al. (2021), which is discussed in the related literature section, models separate worker and entrepreneurship occupations. In their setting, entrepreneurial income can be considered as profits. The government conditions taxes on occupations and, thus, nonlinear taxes on entrepreneurial income correspond to profit taxes. The main policy results of this study closely resemble those in Eeckhout et al. (2021).

\subsection{Heterogeneous wage effects}

This study assumes that high- and low-skilled wages are affected similarly by an increase in market power. Rising market power may asymmetrically affect wages, i.e., due to a disproportionate decline in low-skilled labor demand and asymmetric profit-sharing (Eeckhout 2021, p.115-126). As a result, the government may prefer higher (lower) marginal income taxes on low- (high-) skilled individuals as markups increase in order to reduce skill premia and increase redistribution. To the best of my knowledge, however, the effect of market power on wage inequality has not yet been empirically examined.

\section{Conclusion}

Motivated by the recent empirical evidence, this paper studies the consequences of rising markups for optimal profit and Mirrleesian income taxation. I construct a general equilibrium model with heterogeneous individuals, monopolistically competitive firms and endogenous market entry. An increase in fixed production costs distorts competition, increases equilibrium markups and, thus, reduces the real wages of the individuals. In addition, higher markups imply a distortion of labor supply and generate efficiency losses.

When fixed costs are not deductible from profits, the profit tax can be used to control market entry and markups. In a stylized model with two individuals, I show that the profit tax optimizes the trade-off between its redistributive benefits and adverse competitive effects. Numerical simulations suggest that, as markups rise, the optimal behavior of a utilitarian government is to utilize a higher profit tax rate in order to increase redistribution. Optimal marginal labor income taxes, on the other hand, decline in order to contribute to the growth of the profit tax base. I explore the welfare implications of optimal policies by constructing a counterfactual scenario in which the fixed costs rise, but the government does not respond. Optimally adjusting the policy mixture considerably increases the equilibrium markups. Nonetheless, almost all the individuals enjoy higher indirect utilities with optimal policies.

With perfectly deductible fixed costs, the profit tax becomes ineffective in controlling market entry. In this scenario, I specify an exogenous profit tax rate and 
explore optimal marginal income taxes, which can be used to exercise some control over equilibrium markups. When the profit tax is inoperative, optimal marginal income taxes hardly respond to higher markups and, thus, governmental response does not exhibit increased redistribution.

\section{Appendix}

Proof of Proposition 1 Define the following for later reference:

$$
M R S_{l, z}^{i}:=-\frac{v_{l}^{i}}{u_{z}^{i}} \quad \text { with } \quad i \in\{H, L\}, \quad M \hat{R} S_{l, z}:=-\frac{\hat{v}_{l}}{\hat{u}_{z}} .
$$

In the following, variables that read $x\left(n^{i}\right)$ are replaced by $x^{i}$ for brevity. Considering that there are two discrete individuals, the maximization problem of the government, represented by (13), (14) and (15), implies the following Lagrangian:

$$
\begin{aligned}
\mathcal{L}^{1}= & \sum_{i} f_{i} H\left[u^{i}\left(\frac{c^{i}}{P_{c}}\right)-v^{i}\left(\frac{y^{i}}{n^{i}}\right)\right]+\lambda\left\{u^{H}\left(\frac{c^{H}}{P_{c}}\right)-v^{H}\left(\frac{y^{H}}{n^{H}}\right)-\hat{u}\left(\frac{c^{L}}{P_{c}}\right)+\hat{v}\left(\frac{y^{L}}{n^{H}}\right)\right\} \\
& +\alpha\left\{f_{H}\left(y^{H}-c^{H}\right)+f_{L}\left(y^{L}-c^{L}\right)+\tau(\mu-1) F-R\right\} \\
& +\gamma\{(1-\tau)(\mu-1) F-N \phi\} .
\end{aligned}
$$

In (35), the zero-profit condition, (12), is incorporated as an explicit constraint and, hence, both $\tau$ and $N$ must be considered as control variables. Alternatively, one could recover $N$ as a function of $\tau$ from (12) and only use $\tau$ as a control variable. Additionally, it is assumed that resulting allocation of resources is monotonic and incentive constraint of the low-type does not bind. Finally, because two discrete types are assumed for analytical purposes, explicit incentive constraint of the hightype must be employed (i.e., instead of the differential form given in (15)). Variables of the mimicking agent are denoted by a hat. First-order conditions read:

$$
\begin{gathered}
y^{H}: \quad-\left(f_{H} H_{v}+\lambda\right) v_{l}^{H} \frac{1}{n^{H}}+\alpha\left\{f_{H}+\tau(\mu-1) \frac{\partial F}{\partial y^{H}}\right\}+\gamma(1-\tau)(\mu-1) \frac{\partial F}{\partial y^{H}}=0 \\
y^{L}: \quad-f_{L} H_{v} \frac{1}{n^{L}} v_{l}^{L}+\lambda \hat{v}_{l} \frac{1}{n^{H}}+\alpha\left\{f_{L}+\tau(\mu-1) \frac{\partial F}{\partial y^{L}}\right\}+\gamma(1-\tau)(\mu-1) \frac{\partial F}{\partial y^{L}}=0 \\
c^{H}: \quad\left(f_{H} H_{u}+\lambda\right) \frac{1}{P_{c}} u_{z}^{H}-\alpha f_{H}=0 \\
c^{L}: \quad f_{L} H_{u} \frac{1}{P_{c}} u_{z}^{L}-\lambda \frac{1}{P_{c}} \hat{u}_{z}-\alpha f_{L}=0
\end{gathered}
$$




$$
\begin{gathered}
N: \frac{d P_{c}}{d N} \frac{\partial \mathcal{L}^{1}}{\partial P_{c}}+\alpha \tau \frac{d \mu}{d N} F+\gamma\left\{(1-\tau) \frac{d \mu}{d N} F-\phi\right\}=0, \\
\tau: \quad \alpha(\mu-1) F-\gamma(\mu-1) F=0 .
\end{gathered}
$$

where

$$
\frac{\partial \mathcal{L}^{1}}{\partial P_{c}}=\left\{f_{H} H_{u} u_{z}^{H} z_{P_{c}}^{H}+f_{L} H_{u} u_{z}^{L} z_{P_{c}}^{L}\right\}+\lambda\left\{u_{z}^{H} z_{P_{c}}^{H}-\hat{u}_{z} \hat{z}_{P_{c}}\right\}<0 .
$$

Recall from Section 2.1 that $z^{i}=\frac{c^{i}}{P_{c}}$. Because $z_{P_{c}}^{i}<0$ and the rest of the variables are positive, the first term in (42) is negative. This reflects the direct welfare effect of a higher cost-of-living. The second term arises due to incentive compatibility constraints. For simplicity, consider the quasi-linear preferences used in the numerical simulations: $u_{z}^{H} z_{P_{c}}^{H}-\hat{u}_{z} \hat{z}_{P_{c}}=-\frac{c^{H}}{P_{c}^{2}}+\frac{c^{L}}{P_{c}^{2}}<0$. This represents a further negative welfare effect because mimicking becomes more attractive for the high-type. Thus, $\frac{\partial \mathcal{L}^{1}}{\partial P_{c}}<0$.

Rearrange (40) and use (41), which implies $\alpha=\gamma$, to get:

$$
\frac{d P_{c}}{d N} \frac{\partial \mathcal{L}^{1}}{\partial P_{c}}+\alpha \frac{d \mu}{d N} F=\alpha \phi .
$$

From (12), one can establish that $\phi=\frac{(1-\tau)(\mu-1) F}{N}$. Substituting this into (43) and rearranging gives:

$$
1-\tau=\frac{\frac{d P_{c}}{d N} \frac{\partial \mathcal{L}^{1}}{\partial P_{c}}+\alpha \frac{d \mu}{d N} F}{\alpha(\mu-1) x} .
$$

Multiply both numerator and denominator by $N$. Multiply the first and second term in the numerator, respectively, with $\frac{P_{c}}{P_{c}}$ and $\frac{\mu}{\mu}$ :

$$
1-\tau=\frac{\frac{d P_{c}}{d N} \frac{\partial \mathcal{L}^{1}}{\partial P_{c}} \frac{P_{c}}{P_{c}} N+\alpha \frac{d \mu}{d N} F \frac{\mu}{\mu} N}{\alpha(\mu-1) F} .
$$

Using the definitions of elasticities, one can get the optimal profit tax, (19), together with:

$$
\psi_{P_{c}}=\frac{\partial \mathcal{L}^{1}}{\partial P_{c}} P_{c}, \quad \psi_{\mu}=\frac{\partial \mathcal{L}^{1}}{\partial \mu} \mu=\alpha F \mu
$$

Inequality $\psi_{P_{c}}<0$ follows because $\frac{\partial \mathcal{L}^{1}}{\partial P_{c}}<0, P_{c}>0 . \psi_{\mu}>0$ due to $\alpha>0$ (Lagrange multiplier), $\mu>0$ and $F>0$. Partial derivative $\frac{\partial \mathcal{L}^{1}}{\partial P_{c}}$ represents the welfare effect of a unit change in prices (see (42)). Multiplication with $P_{c}$ translates this into the welfare effect of a percent change in $P_{c}$. Similarly, utilizing $\alpha=\gamma$ equivalence, one can 
establish $\frac{\partial \mathcal{L}^{1}}{\partial \mu}=\alpha F$. Thus, in response to a unit change in $\mu$, the welfare effect is $\alpha F$. Multiplication with $\mu$ yields the welfare effect of a percent change in $\mu$.

In order to obtain the optimal marginal income taxes, divide (36) by (38) side-by-side:

$$
-\frac{v_{l}^{H}}{u_{z}^{H} n^{H}} P_{c}=\frac{-\alpha\left\{f_{H}+\tau(\mu-1) \frac{\partial F}{\partial y^{H}}\right\}+\gamma(1-\tau)(\mu-1) \frac{\partial F}{\partial y^{H}}}{\alpha f_{H}} .
$$

Use $\frac{\partial F}{\partial y^{H}}=f_{H}$ due to (7), $\alpha=\gamma$ and (18) to obtain:

$$
T^{\prime}\left(y^{H}\right)=-\tau(\mu-1)-(1-\tau)(\mu-1) .
$$

Rearranging yields (20).

Divide (37) by (39) side-by-side:

$$
-\frac{v_{l}^{L}}{u_{z}^{L} n^{L}} P_{c}=\frac{-\lambda \hat{v}_{l} \frac{1}{n^{H}}-\alpha\left\{f_{L}+\tau(\mu-1) \frac{\partial F}{\partial y^{L}}\right\}-\gamma(1-\tau)(\mu-1) \frac{\partial F}{\partial y^{L}}}{\lambda \frac{1}{P_{c}} \hat{u}_{z}+\alpha f_{L}} .
$$

Rearrange and use $\frac{\partial F}{\partial y^{L}}=f_{L}$ :

$$
-\alpha f_{L} \frac{v_{l}^{L}}{u_{z}^{L} n^{L}} P_{c}-\lambda \frac{1}{P_{c}} \hat{u}_{z} \frac{v_{l}^{L}}{u_{z}^{L} n^{L}} P_{c}=-\lambda \hat{v}_{l} \frac{1}{n^{H}}-\alpha f_{L}-\alpha \tau(\mu-1) f_{L}-\gamma(1-\tau)(\mu-1) f_{L} .
$$

Divide by $\alpha f_{L}$, use that $\gamma=\alpha$ and (18):

$$
T^{\prime}\left(y^{L}\right)=\frac{\lambda}{\alpha f_{L}} \hat{u}_{z} \frac{v_{l}^{L}}{u_{z}^{L} n^{L}}-\frac{\lambda}{\alpha f_{L}} \hat{v}_{l} \frac{1}{n^{H}}-(\mu-1) .
$$

Utilizing the definitions provided in (34) and rearranging yields:

$$
T^{\prime}\left(y^{L}\right)=\frac{\lambda}{\alpha f_{L}} \hat{u}_{z} \frac{1}{n^{L}}\left(M \hat{R} S_{l, z} \frac{n^{L}}{n^{H}}-M R S_{l, z}^{L}\right)-(\mu-1) .
$$

Equation (52) represents the optimal marginal income tax on the high-type. The first term is referred to as the standard Stiglitz (1982) term, $T_{s}^{\prime}$, in the main text.

Proof of Proposition 2 Similar to the previous proof, variables that read $x\left(n^{i}\right)$ are replaced by $x^{i}$. The Lagrangian of the problem reads:

$$
\begin{aligned}
\mathcal{L}^{2}= & \sum_{i} f_{i} H\left[u^{i}\left(\frac{c^{i}}{P_{c}}\right)-v^{i}\left(\frac{y^{i}}{n^{i}}\right)\right]+\lambda\left\{u^{H}\left(\frac{c^{H}}{P_{c}}\right)-v^{H}\left(\frac{y^{H}}{n^{H}}\right)-\hat{u}\left(\frac{c^{L}}{P_{c}}\right)+\hat{v}\left(\frac{y^{L}}{n^{H}}\right)\right\} \\
& +\alpha\left\{f_{H}\left(y^{H}-c^{H}\right)+f_{L}\left(y^{L}-c^{L}\right)+\tau[(\mu-1) F-N \phi]-R\right\} .
\end{aligned}
$$


Notice that the zero-profit condition, (12), does not enter as a constraint because $N\left(y\left(n^{H}\right), y\left(n^{L}\right)\right)$ is maintained due to the zero-profit condition. First-order conditions with respect to $c^{H}$ and $c^{L}$ are the same as (38) and (39). Remaining conditions read:

$$
\begin{aligned}
& y^{H}: \quad-\left(f_{H} H_{v}+\lambda\right) v_{l}^{H} \frac{1}{n^{H}}+\alpha\left\{f_{H}+\tau(\mu-1) \frac{\partial F}{\partial y^{H}}\right\}+\frac{\partial N}{\partial y^{H}} \Lambda_{N}=0, \\
& y^{L}: \quad-f_{L} H_{v} \frac{1}{n^{L}} v_{l}^{L}+\lambda \hat{u}_{l} \frac{1}{n^{H}}+\alpha\left\{f_{L}+\tau(\mu-1) \frac{\partial F}{\partial y^{L}}\right\}+\frac{\partial N}{\partial y^{L}} \Lambda_{N}=0 .
\end{aligned}
$$

with $\Lambda_{N}$ defined in (28). Divide (53) by (38) side-by-side using that $\frac{\partial F}{\partial y^{H}}=f_{H}$ :

$$
-\frac{v_{l}^{H}}{u_{z}^{H} n^{H}} P_{c}=\frac{-\alpha f_{H}-\alpha \tau(\mu-1) f_{H}-\frac{\partial N}{\partial y^{H}} \Lambda_{N}}{\alpha f_{H}} .
$$

Use (18) to recover the expression in (26).

Divide (54) by (39) side-by-side and use that $\frac{\partial F}{\partial y^{L}}=f_{L}$ :

$$
-\frac{v_{l}^{L}}{u_{z}^{L} n^{L}} P_{c}=\frac{-\lambda \hat{v}_{l} \frac{1}{n^{H}}-\alpha\left\{f_{L}+\tau(\mu-1) f_{L}\right\}-\frac{\partial N}{\partial y^{L}} \Lambda_{N}}{\lambda \frac{1}{P_{c}} \hat{u}_{z}+\alpha f_{L}} .
$$

Rearrange to get:

$$
-\lambda \hat{u}_{z} \frac{v_{l}^{L}}{u_{z}^{L} n^{L}}-\alpha f_{L} \frac{v_{l}^{L}}{u_{z}^{L} n^{L}} P_{c}=-\alpha f_{L}-\lambda \hat{v}_{l} \frac{1}{n^{H}}-\alpha f_{L} \tau(\mu-1)-\frac{\partial N}{\partial y^{L}} \Lambda_{N} .
$$

Divide by $\alpha f_{L}$ and use (18) to obtain:

$$
T^{\prime}\left(y^{L}\right)=\frac{\lambda}{\alpha f_{L}} \hat{u}_{z} \frac{v_{l}^{L}}{u_{z}^{L} n^{L}}-\frac{\lambda}{\alpha f_{L}} \hat{v}_{l} \frac{1}{n^{H}}-\tau(\mu-1)-\frac{\partial N}{\partial y^{L}} \frac{\Lambda_{N}}{\alpha f_{L}} .
$$

Use (34) to recover the expression in (27):

$$
T^{\prime}\left(y^{L}\right)=\frac{\lambda}{\alpha f_{L}} \hat{u}_{z} \frac{1}{n^{L}}\left(\hat{M R} S_{l, z} \frac{n^{L}}{n^{H}}-M R S_{l, z}^{L}\right)-\tau(\mu-1)-\frac{\partial N}{\partial y^{L}} \frac{\Lambda_{N}}{\alpha f_{L}} .
$$

The first term is referred to as the Stiglitz (1982) term, $T_{s}^{\prime}$, in the main text.

$\Lambda_{N}$ is given in (28). In this setting, it is more convenient to express Price Effect and Tax Base Effect via partial derivatives. Thus, welfare effects in response to percent changes, $\psi_{P_{c}}$ and $\psi_{\mu}$, are replaced by terms that reflect the welfare effects in response to unit changes. However, the intuition behind the two effects is intact. Initially, recall that $\frac{\partial N}{\partial y\left(n^{i}\right)}>0$. The expression $\frac{d P_{c}}{d N} \frac{\partial \mathcal{L}^{1}}{\partial P_{c}}>0$ because both derivatives are negative. Intuitively, a greater Price Effect contributes to a decline in optimal marginal income taxes in order to increase profits, encourage market entry, and reduce the cost-of-living. Similar to Section 3.2, the Tax Base Effect incorporates the 
change in markups in response to an increase in the equilibrium number of firms. Additionally, in this setting, a higher number of firms reduces the profit tax base further by $\phi$ due to deductability of the fixed costs.

Funding Open Access funding enabled and organized by Projekt DEAL.

Open Access This article is licensed under a Creative Commons Attribution 4.0 International License, which permits use, sharing, adaptation, distribution and reproduction in any medium or format, as long as you give appropriate credit to the original author(s) and the source, provide a link to the Creative Commons licence, and indicate if changes were made. The images or other third party material in this article are included in the article's Creative Commons licence, unless indicated otherwise in a credit line to the material. If material is not included in the article's Creative Commons licence and your intended use is not permitted by statutory regulation or exceeds the permitted use, you will need to obtain permission directly from the copyright holder. To view a copy of this licence, visit http://creativecommons.org/licen ses/by/4.0/.

\section{References}

Acemoglu, D., LeLarge, C., and Restrepo, P. (2020). Competing with Robots: Firm-Level Evidence from France. National Bureau of Economic Research Working Paper 26738.

Atalay, E. (2017). How important are sectoral shocks? American Economic Journal: Macroeconomics, 9(4), 254-280.

Atesagaoglu, O. E. and Yazici, H. (2020). Optimal Fiscal Policy in the Presence of Declining Labor Share. Working Paper.

Auriol, E., \& Warlters, M. (2005). Taxation base in developing countries. Journal of Public Economics, 89(4), 625-646.

Autor, D., Dorn, D., Katz, L. F., Patterson, C., \& Reenen, J. V. (2020). The fall of the labor share and the rise of superstar firms. The Quarterly Journal of Economics, 135(2), 645-709.

Avdiu, B. (2018). Optimal Capital and Labor Income taxation in Small and Developing Countries. MPRA Paper No. 89266.

Barkai, S. (2020). Declining labor and capital shares. Journal of Finance, 75(5), 2421-2463.

Bernard, A. B., Eaton, J., Jensen, J. B., \& Kortum, S. (2003). Plants and productivity in international trade. American Economic Review, 93(4), 1268-1290.

Bessen, J. (2017). Industry Concentration and Information Technology (pp. 17-41). Law and Economics Research Paper, No: Boston Univ. School of Law.

Bilbiie, F. O., Ghironi, F., \& Melitz, M. J. (2019). Monopoly power and endogenous product variety: distortions and remedies. American Economic Journal: Macroeconomics, 11(4), 140-174.

Blaum, J., Lelarge, C., \& Peters, M. (2018). The gains from input trade with heterogeneous importers. American Economic Journal: Macroeconomics, 10(4), 77-127.

Bloom, N., Jones, C. I., Reenen, J. V., \& Webb, M. (2020). Are ideas getting harder to find? American Economic Review, 110(4), 1104-1144.

Boar, C. and Midrigan, V. (2019). Markups and Inequality. National Bureau of Economic Research Working Paper 25952.

Bowley, A. L. (1924). Mathematical Groundwork of Economics: An Introductory Treatise. Oxford: Clarendon Press.

Brakman, S., \& Heijdra, B. J. (2004). The Monopolistic Competition Revolution In Retrospect. Cambridge: Cambridge University Press.

Chetty, R. (2012). Bounds on elasticities with optimization frictions: a synthesis of micro and macro evidence on labor supply. Econometrica, 80(3), 969-1018.

Ciliberto, F., \& Williams, J. W. (2014). Does multimarket contact facilitate tacit collusion? inference on conduct parameters in the airline industry. The RAND Journal of Economics, 45(4), 764-791.

Colciago, A. and Mechelli, R. (2020). Competition and Inequality. Working Paper. 
Colciago, A. (2016). Endogenous market structures and optimal taxation. The Economic Journal, 126(594), 1441-1483.

Coto-Martínez, J., Sánchez-Losada, F., \& Garriga, C. (2007). Optimal taxation with imperfect competition and aggregate returns to specialization. Journal of the European Economic Association, 5(6), 1269-1299.

da Costa, C. E., \& Maestri, L. J. (2018). Optimal mirrleesian taxation in non-competitive labor markets. Economic Theory, 68(4), 845-886.

Decker, R. A., Haltiwanger, J., Jarmin, R. S., \& Miranda, J. (2016). Where has all the skewness gone? the decline in high-growth (young) firms in the U.S. European Economic Review, 86, 4-23.

Dharmapala, D. (2014). What do we know about base erosion and profit shifting? a review of the empirical literature. Fiscal Studies, 35(4), 421-448.

Diamond, P. A. (1998). Optimal income taxation: an example with u-shaped pattern of optimal marginal tax rates. The American Economic Review, 88(1), 83-95.

Dixit, A. K., \& Stiglitz, J. E. (1977). Monopolistic competition and optimum product diversity. The American Economic Review, 67(3), 297-308.

Eaton, J., Kortum, S., \& Kramarz, F. (2011). An anatomy of international trade: evidence from French firms. Econometrica, 79(5), 1453-1498.

Ebert, U. (1992). A reexamination of the optimal nonlinear income tax. Journal of Public Economics, 49(1), 47-73.

Eeckhout, J., Fu, C., Weng, X., and Li, W. (2021). Optimal Taxation and Market Power. CEPR Discussion Paper No. DP16011.

Eeckhout, J. (2021). The Profit Paradox. USA: Princeton University Press.

Epifani, P., \& Gancia, G. (2017). Global imbalances revisited: the transfer problem and transport costs in monopolistic competition. Journal of International Economics, 108, 99-116.

Etro, F. (2018). Macroeconomics with endogenous markups and optimal taxation. Southern Economic Journal, 85(2), 378-406.

Gruber, J., \& Saez, E. (2002). The elasticity of taxable income: evidence and implications. Journal of Public Economics, 84(1), 1-32.

Grullon, G., Larkin, Y., \& Michaely, R. (2019). Are US industries becoming more concentrated? Review of Finance, 23(4), 697-743.

Gürer, E. (2021). Rising Markups and Optimal Redistributive Taxation. Available at SSRN: https://ssrn. com/abstract $=3792769$.

Gutiérrez, G. and Philippon, T. (2019). The Failure of Free Entry. National Bureau of Economic Research Working Paper 26001.

Hall, R. (2018). New Evidence on the Markup of Prices over Marginal Costs and the Role of Mega-Firms in the US Economy. National Bureau of Economic Research Working Paper 24574.

Hariton, C., \& Piaser, G. (2007). When redistribution leads to regressive taxation. Journal of Public Economic Theory, 9(4), 589-606.

Heathcote, J., Storesletten, K., \& Violante, G. L. (2017). Optimal tax progressivity: An analytical framework. The Quarterly Journal of Economics, 132(4), 1693-1754.

Hobijn, B., \& Nechio, F. (2018). Sticker shocks: Using VAT changes to estimate upper-level elasticities of substitution. Journal of the European Economic Association, 17(3), 799-833.

Hopenhayn, H., Neira, J., and Singhania, R. (2018). From Population Growth to Firm Demographics: Implications for Concentration, Entrepreneurship and the Labor Share. National Bureau of Economic Research Working Paper 25382.

Hummel, A. J. (2020). Monopsony Power, Income Taxation and Welfare. Working Paper.

Huneeus, F. (2018). Production Network Dynamics and the Propagation of Shocks. Working Paper.

Kanbur, R., \& Tuomala, M. (2013). Relativity, inequality, and optimal non-linear income taxation. International Economic Review, 54(4), 1199-1217.

Kaplow, L. (2019). Market Power and Income Taxation. National Bureau of Economic Research Working Paper 25382.

Karahan, F., Pugsley, B., and Sahin, A. (2019). Demographic Origins of the Startup Deficit. National Bureau of Economic Research Working Paper 25874.

Kushnir, A. I. and Zubrickas, R. (2019). Optimal Income Taxation with Endogenous Prices. Working Paper.

Lockwood, B. B., \& Weinzierl, M. (2015). De Gustibus non est Taxandum: Heterogeneity in preferences and optimal redistribution. Journal of Public Economics, 124, 74-80. 
Loecker, J. D. and Eeckhout, J. (2018). Global Market Power. National Bureau of Economic Research Working Paper 24768.

Loecker, J. D., Eeckhout, J., \& Unger, G. (2020). The rise of market power and the macroeconomic implications. The Quarterly Journal of Economics, 135(2), 561-644.

OECD (2017). Revenue Statistics 1965-2016. OECD Publishing, Paris.

Peter, A. and Ruane, C. (2020). The Aggregate Importance of Intermediate Input Substitutability. Working Paper.

Pugsley, B. W. and Sahin, A. (2018). Grown-up Business Cycles. The Review of Financial Studies, 32(3), $1102-1147$.

Raval, D. R. (2019). The micro elasticity of substitution and non-neutral technology. The RAND Journal of Economics, 50(1), 147-167.

Redding, S. J. and Weinstein, D. E. (2016). Measuring Aggregate Price Indexes with Taste Shocks: Theory and Evidence for CES Preferences. National Bureau of Economic Research Working Paper 22479.

Ridder, M. D. (2020). Market Power and Innovation in the Intangible Economy. Working Paper.

Rothschild, C., \& Scheuer, F. (2013). Redistributive taxation in the roy model. The Quarterly Journal of Economics, 128(2), 623-668.

Saez, E. (2001). Using elasticities to derive optimal income tax rates. The Review of Economic Studies, 68(1), 205-229.

Saez, E., \& Zucman, G. (2016). Wealth inequality in the united states since 1913: evidence from capitalized income tax data. The Quarterly Journal of Economics, 131(2), 519-578.

Scheuer, F. (2014). Entrepreneurial taxation with endogenous entry. American Economic Journal: Economic Policy, 6(2), 126-163.

Schmitt, M. (2018). Multimarket contact in the hospital industry. American Economic Journal: Economic Policy, 10(3), 361-387.

Stiglitz, J. E. (1982). Self-selection and pareto efficient taxation. Journal of Public Economics, 17(2), 213-240.

Tørsløv, T. R., Tier, L. S., and Zucman, G. (2018). The Missing Profits of Nations. National Bureau of Economic Research Working Paper 24701.

Zucman, G. (2014). Taxing across borders: Tracking personal wealth and corporate profits. Journal of Economic Perspectives, 28(4), 121-148.

Publisher's Note Springer Nature remains neutral with regard to jurisdictional claims in published maps and institutional affiliations. 